\title{
PENGARUH ORIENTASI BELANJA DAN KUALITAS WEB TERHADAP KEPUTUSAN PEMBELIAN MELALUI WORD OF MOUTH COMMUNICATIONS SEBAGAI VARIABEL INTERVENING PADA ONLINE SHOPPING SHOPEE (STUDI KASUS PADA MAHASISWA UNIVERSITAS SARJANAWIYATA TAMANSISWA YOGYAKARTA) Anis Lelani ${ }^{1}$, Henny Welsa ${ }^{2}$, Putri Dwi Cahyani ${ }^{3}$
}

Fakultas Ekonomi Universitas Sarjanawiyata Tamansiswa Yogyakarta Email anislelani@gmail.com

\begin{abstract}
This study aims to examine whether word of mouth communications mediates the relationship between shopping orientation and purchasing decisions, and whether word of mouth communications also mediates web quality and purchasing decisions. The study took samples from the students of the Faculty of Economics, Sarjanawiyata Tamansiswa Yogyakarta University. The sampling method is nonprobability, and the sampling technique uses non probability sampling. Data collection was carried out through questionnaires to respondents. The number of questionnaires processed was 100 questionnaires. Data were analyzed using primary data. The results showed that the variable word of mouth communications can influence shopping orientation, web quality and purchasing decisions. purchasing decisions have a significant effect on shopping orientation and web quality. Word of mouth communications significantly influence the purchasing decisions.
\end{abstract}

Key words: Shopping Orientation, Web Quality, Word Of Mouth Communications, Purchasing Decisions

\section{PENDAHULUAN}

Di era globalisasi seperti sekarang ini, internet telah mengambil peran penting dalam aktivitas manusia di setiap harinya. Dengan adanya internet semua informasi apapun di media sosial mudah di dapatkan dab juga cepat, bahkan dengan semua fasilitas yang disediakan oleh internet dapat mempermudah segala urusan kita. Tidak jarang sekarang internet juga banyak digunakan untuk media belanja dan pemasaran secara online suatu produk.

Pertumbuhan bisnis online saat ini sangat berkembang pesat, sehingga dapat memudahkan konsumen untuk memenuhi kebutuhannya. Internet juga terbukti dapat mempermudah dalam berkomunikasi dan memperoleh informasi dengan tepat dan akurat. Saat ini media sosial dijadikan salah satu gerakan baru di dunia pemasaran, berbagai media sosial muncul dengan keunggulan yang dimiliki.

Media belanja online di marketplace sepertis Shopee contohnya dimana media belanja online memberikan banyak manfaat bagi pemasar itu sendiri yaitu dapat lebih mudah dalam memasarkan produknya dimana pemasar dapat mengunggah gambar produknya di media belanja online shopee yang secara otomatis gambar maupun informasi secara detail dari produk yang dipasarkan dapat dilihat oleh para calon konsumen. Manfaat lainnya bagi pengusaha itu sendiri adalah dapat menghemat biaya periklanan produk, mudah mengetahui respon.

Di Indonesia, melakukan perbelanja secara online telah menjadi kebiasaan banyak pihak untuk memperoleh barang. Pertumbuhan e-commerce yang terus meningkat di Indonseia membuat Shopee ikut meramaikan industri ini. Shopee merupakan aplikasi mobile marketplace pertama bagi konsumen ke konsumen (C2C) yang aman, menyenangkan, mudah, dan praktis 
dalam jual beli. Shopee memulai masuk pasar di Indonesia pada akhir tahun bulan Mei 2015 dan shopee memulai beroperasi akhir bulan Juni 2015.

\section{TINJAUAN PUSTAKA DAN PENGEMBANGAN HIPOTESIS Orientasi belanja}

Munculnya kegiatan belanja online, memberikan dampak terhadap perilaku belanja online itu sendiri, konsumen mungkin berbeda dalam hal orientasi belanja mereka. Stone (1954) dalam Kurnia (2016). Li et al dalam Ling (2010), membuat konsep orientasi belanja sebagai bagian tertentu dari gaya hidup pembelanja yang mencakup aktivitas berbelanja, pendapat, dan minat. Berdasarkan hal tersebut dapat dikatakan bahwa orientasi belanja merupakan bagian dari gaya hidup individu dengan menekankan pada kegiatan berbelanja individu dan dapat menggambarkan keinginan dan kebutuhan individu ketika melakukan kegiatan berbelanja. Orientasi belanja memiliki tujuh dimensi, yaitu: Shopping enjoyment, Brand consciousness, Price consciousness, Shopping confidenc, Convinience/time consciousness, In-home shopping tendenc, Brand/store loyalty

\section{Kualitas Web}

Kualitas website adalah hal yang sangat perlu diperhatikan oleh semua yang melakukan proses penjualan secara online, salah satunya online travel agent. Kualitas website merupakan pengaruh penting dalam penjualan yang memeiliki pengaruh penting terhadap konsumen. Bavarsad et al. (2013) menjelaskan bahwa website yang baik memiliki kualitas operasional yang kuat untuk pembeli melakukan e-shopping mereka dengan mudah dan efisiensi. kualitas web memiliki tiga indikator yaitu : Kegunaan, Kualitas informasi, Interaksi

\section{Word Of Mouth Communication (WOM)}

Word of mouth mommunication (WOM) atau komunikasi dari mulut ke mulut merupakan proses komunikasi yang berupa rekomendasi baik secara individu maupun kelompok terhadap suatu produk atau jasa yang bertujuan untuk memberikan informasi secara personal Kotler dan Keller (2012). Komunikasi yang komunikatif sangat dibutuhkan dalam membangun suatu relasi yang baik antar individu dalam keluarga dan masyarakat. Demikian halnya dalam setiap organisasi, bahwa komunikasi merupakan hal yang amat penting sebagai sarana efektif. Terdapat lima dimensi atau elemen dasar word of mouth yang dikenal dengan 5T, yaitu: Talkers (pembicara), Topics (topik), Tools (alat), Talking part (partisipasi) dan Tracking (pengawasan).

\section{Keputusan Pembelian}

Keputusan konsumen dalam melakukan pembelian suatu produk merupakan suatu tindakan yang dilakukan oleh setiap individu konsumen dalam mengambil keputusan membeli. Keputusan untuk membeli atau tidak membeli merupakan bagian dari unsur utama pada diri individu konsumen yang disebut behavior dimana mereka merujuk kepada tindakan fisik yang nyata. Keputusan pembelian sebagai langkah utama untuk konsumen secara aktual melakukan pembelian suatu produk menurut Tjiptono (2012:193). Indikator dari keputusan pembelian: pilihan produk, pilihan merek, pilihan penyalur, waktu pembelian., jumlah pembelian.

\section{PENGEMBANGAN HIPOTESIS}

\section{Pengaruh Orientasi Belanja terhadap Word of Mouth Communications}

Orientasi belanja berpengaruh signifikan terhadap word of mouth communication hipotesis ini sejalan dengan penelitian yang dilakukan oleh (Wahyuningsih, 2007). Ketika konsumen memiliki orientasi berbelanja yang tinggi maka akan berpengaruh pada terciptanya word of mouth communications yang positif dengan demikian apabila konsumen memiliki 
orientasi belanja yang positif dan puas terhadap pelayanan suatu situs belanja online maka akan menghasilkan suatu word of mouth communications yang positif.

H1: Orientasi Belanja berpengaruh positif dan terhadap Word Of Mouth Communications

Pengaruh Kualitas Web terhadap Word of Mouth Communications

kualitas web berpengaruh secara langsung terhadap word of mouth communications hipotesis ini sejalan dengan penelitian yang dilakukan oleh (Sarwono dan Prihartono, 2012), yang mana konsumen akan menilai sebaik mana kualitas web dari situs belanja online untuk menentukan word of mouth communications. Ketika konsumen memberikan word of mouth communications yang baik dari kualitas web yang diberikan oleh suatu situs online tersebut maka secara bersamaan akan membentuk word of mouth communications yang positif.

H2 : kualitas website berpengaruh positif dan signifikan terhadap word of mouth communications.

\section{Pengaruh Orientasi belanja terhadap Keputusan Pembelian}

Orientasi belanja berpengaruh secara langsung terhadap keputusan pembelian, hipotesis ini sejalan dengan penelitian yang dilakukan oleh (Susanti, Yunus, dan Chan, (2015) menyatakan bahwa terdapat hubungan yang signifikan antara variabel orientasi belanja terhadap keputusan pembelian.

H3 : Orientasi Belanja berpengaruh positif dan terhadap Keputusan Pembelian

Pengaruh Kualitas Web terhadap Keputusan Pembelian

Kualitas web berpengaruh signifikan terhadap keputusan pembelian, hasil temuan dalam penelitian ini juga memperkuat temuan dari (Suhari, 2008) yang menemukan bahwa kualitas web berpengaruh signifikan terhadap keputusan pembelian, dengan adanya kualitas web yang dinilai baik oleh konsumen akan mempengaruhi keputusan pembelian suatu produk di situs online H4 : kualitas web berpengaruh signifikan terhadap keputusan pembelian

\section{Pengaruh Word of Mouth Communications terhadap Keputusan Pembelian}

Menurut Zhou dan Adjei (2010 word of mouth communications berpengaruh terhadap terhadap keputusan pembelian. Hipotesis ini sejalan dengan penelitian yang dilakukan oleh (Zhou dan Adjei, 2010) menyatakan bahwa word of mouth communications memiliki pengaruh yang signifikan terhadap keputusan pembelian

H5 : Word Of Mouth Communications berpengaruh signifikan terhadap Keputusan Pembelian.

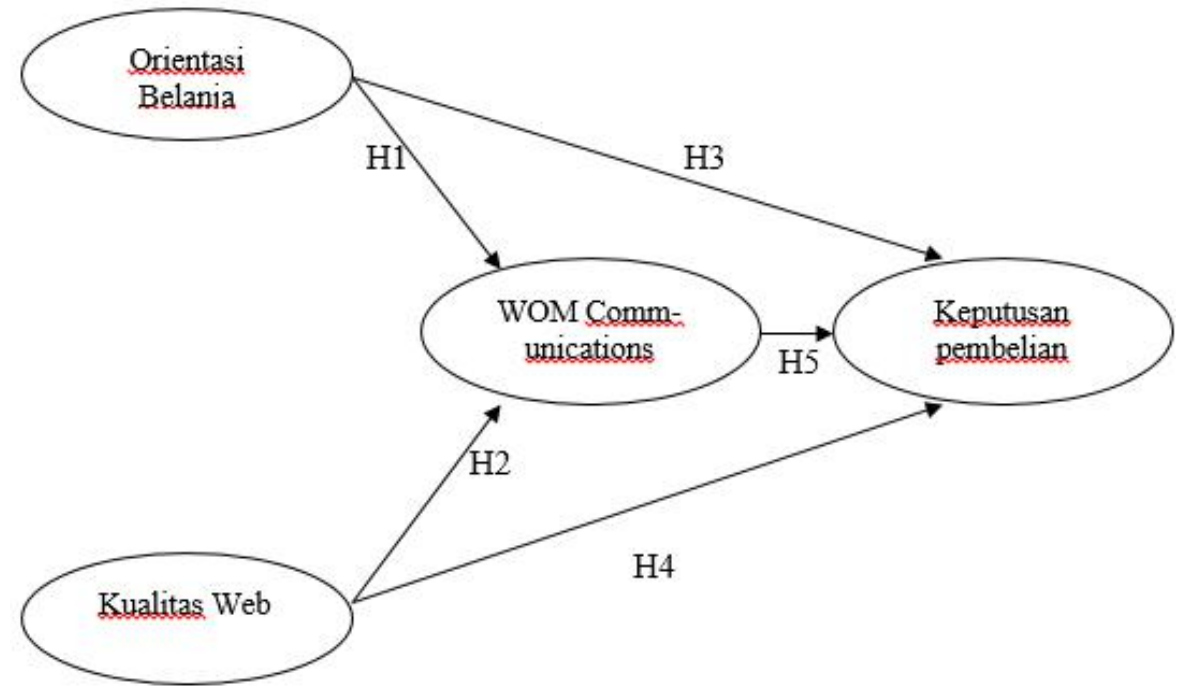




\section{METODE PENELITIAN}

Penelitian ini bersifat explanatory research metode pengumpulan data dalam penelitian ini menggunakan metode kuesioner dengan instrumen pengumpulan data berupa kuesioner. Populasi dalam penelitian ini merupakan mahasiswa \& mahasiswi yang berada dilingkungan kampus Universitas Sarjanawiyata Tamansiswa yang menggunakan produk shopee. Skala pengukuran dalam penelitian ini adalah skala likert. Dalam peneliti ini mengambil sejumlah 100 orang sebagai pengambilan sampel ini menggunakan (Siregar, 2014:62)

\section{HASIL DAN PEMBAHASAN}

$$
n=\frac{(\mathrm{Z} \alpha / 2)^{2} \mathrm{p} \cdot \mathrm{q}}{\mathrm{e}^{2}}
$$

Tabel 1 Jenis Kelamin, Usia \& Program Studi

\begin{tabular}{|c|c|c|c|c|c|c|c|c|}
\hline Jenis Kelamin & $\mathrm{F}$ & $\%$ & Usia & $\mathrm{F}$ & $\%$ & Prodi & $\mathrm{F}$ & $\%$ \\
\hline Laki-laki & 28 & 28,0 & 18 tahun & 1 & 1.0 & Manajemen & 68 & 68.0 \\
\hline \multirow[t]{6}{*}{ Perempuan } & 72 & 72,0 & 19 tahun & 21 & 21.0 & Akuntansi & 32 & 32.0 \\
\hline & & & 20 Tahun & 41 & 41.0 & & & \\
\hline & & & 21 tahun & 27 & 27.0 & & & \\
\hline & & & 22 tahun & 7 & 7.0 & & & \\
\hline & & & 23 tahun & 2 & 2.0 & & & \\
\hline & & & 25 tahun & 1 & 1.0 & & & \\
\hline
\end{tabular}

Berdasarkan Tabel 1 menunjukan bahwa dari 100 responden mahasiswa Universitas Sarjanawiyata Tamansiswa Yogyakarta yang menggunakan produk shopee mayoritas adalah perempuan dengan presentasi 72 dengan rata-rata usia pengguna produk shopee di kalangan mahasiswa Universitas Sarjanawiyata Tamansiswa Yogyakarta berusia 20 tahun dengan angka presentase 41\%. Dan pengguna dari Fakultas Ekonomi Universitas Sarjanawiyata Tamansiswa Yogyakarta menduduki angka paling tinggi adalah mahasiswa prodi manajemen dengan nilai presentasi $68 \%$.

Tabel 2 Uji Validitas dan Reliabilitas

\begin{tabular}{|c|c|c|c|c|c|c|c|}
\hline $\begin{array}{c}\text { Oerientasi } \\
\text { belanja }\end{array}$ & $\begin{array}{c}\text { Pearson } \\
\text { Correlation } \\
\end{array}$ & $\begin{array}{c}\text { Kualiytas } \\
\text { web }\end{array}$ & $\begin{array}{c}\text { Pearson } \\
\text { Correlation }\end{array}$ & $\begin{array}{c}\text { Word of mouth } \\
\text { communications }\end{array}$ & $\begin{array}{c}\text { Pearson } \\
\text { Correlation }\end{array}$ & $\begin{array}{l}\text { Keputusan } \\
\text { pembelian }\end{array}$ & $\begin{array}{c}\text { Pearson } \\
\text { Correlation }\end{array}$ \\
\hline OB1 & 0.543 & WK1 & 0.669 & WOM1 & 0.666 & KP1 & 0.599 \\
\hline OB2 & 0.591 & KW2 & 0.652 & WOM2 & 0.509 & KP2 & 0.566 \\
\hline OB3 & 0.592 & KW3 & 0.633 & WOM3 & 0.647 & KP3 & 0.380 \\
\hline OB4 & 0.627 & KW4 & 0.675 & WOM4 & 0.617 & KP4 & 0.547 \\
\hline OB5 & 0.618 & KW5 & 0.681 & WOM5 & 0.576 & KP5 & 0.527 \\
\hline OB6 & 0.579 & KW6 & 0.635 & WOM6 & 0.620 & KP6 & 0.552 \\
\hline OB7 & 0.606 & & & WOM7 & 0.490 & KP7 & 0.327 \\
\hline OB8 & 0.654 & & & WOM8 & 0.671 & KP8 & 0.426 \\
\hline OB9 & 0.628 & & & WOM9 & 0.556 & KP9 & 0.389 \\
\hline OB10 & 0.573 & & & WOM10 & 0.632 & KP10 & 0.320 \\
\hline OB11 & 0.587 & & & & & & \\
\hline OB12 & 0.531 & & & & & & \\
\hline OB13 & 0.664 & & & & & & \\
\hline OB14 & 0.498 & & & & & & \\
\hline \multicolumn{8}{|c|}{ Cronbach's Alpha } \\
\hline \multicolumn{2}{|c|}{0.855} & \multicolumn{2}{|c|}{0.736} & \multicolumn{2}{|c|}{0.798} & \multicolumn{2}{|c|}{0.796} \\
\hline
\end{tabular}


Hasil dari uji validitas dapat diketahi dari tabel 2 menunjukan bahwa pernyataan pada masing-masing indikor dari variabel bebas dengan nilai Pearson Correlation melebihi nilai dari $\mathrm{r}$ tabel, sehingga butir pernyataan tersebut dikatakan valid.

Tabel 3 Uji Asumsi Klasik

\begin{tabular}{|c|c|c|c|c|c|c|}
\hline \multirow[t]{2}{*}{ Model } & \multicolumn{2}{|c|}{ Variabel } & Normalitas & \multicolumn{2}{|c|}{ Multikolonieritas } & \multirow{2}{*}{$\begin{array}{c}\text { Heterokedastisitas } \\
\text { Sig. }\end{array}$} \\
\hline & Bebas & Terikat & Sig. & Tol. & VIF & \\
\hline \multirow[t]{2}{*}{1} & OB & \multirow[t]{2}{*}{ WOM } & \multirow[t]{2}{*}{0.200} & 0.535 & 1.869 & 0.290 \\
\hline & KW & & & 0.535 & 1.869 & 0.926 \\
\hline \multirow[t]{3}{*}{2} & OB & \multirow{3}{*}{$\mathrm{KP}$} & \multirow{3}{*}{0.200} & 0.430 & 2.328 & 0.439 \\
\hline & KW & & & 0.418 & 2.393 & 0.461 \\
\hline & WOM & & & 0.377 & 2.651 & 0.214 \\
\hline
\end{tabular}

Berdasarkan tabel diatas dapat diketahui bahwa data tersebut berdistribusi secara normal dengan hasil sig. $0,200>0,05$, serta tidak mengalami multikolonieritas dengan nilai tolerance $>$ 0,05 dan nilai $\mathrm{VIF}<10$ dan tidak mengalami heterokedastisitas.

Tabel 4 Pengujian Hipotesis

\begin{tabular}{lllccccrrr}
\hline Model & Variabel & \multicolumn{3}{c}{$\begin{array}{l}\text { Stand. } \\
\text { Coeff. }\end{array}$} & \multicolumn{1}{c}{} & \multicolumn{2}{c}{ Keof. Detr. } \\
& & Bebas & Terikat & Beta & t & Sig. & F & Sig. & Adj. R Sq \\
\hline 1 & OB & WOM & 0.416 & 4.881 & 0.000 & 80.069 & $.000^{\text {b }}$ & 0,623 \\
& KW & & 0.444 & 5.212 & 0.000 & & & 0.322 \\
\hline 2 & OB & KP & 0.125 & 0.975 & 0.332 & 15.232 & $.000^{\text {b }}$ & \\
& KW & & 0.212 & 1.635 & 0.105 & & & \\
& WOM & & 0.290 & 2.118 & 0037 & & & \\
\hline
\end{tabular}

Berdasarkan tabel 4.21 menunjukan $\mathrm{H} 1$ diterima dengan nilai sig. $0,000<0,05$ dan $\mathrm{t}$ hitung 4,881 $>0,677$. H2 diterima dengan nilai sig. $0,000<0,05$ dan thitung 4,881 >0,677. H3 diterima dengan nilai sig 0,332<0,05 dan t hitung $0,975<0,677$. H4 diterima dengan nilai sig $0,105<0,05$ dan $t$ hitung 1,632<0,677. H5 diterima dengan nilai sig. $0,000<0,05$ dan $\mathrm{t}$ hitung $2,118>0,677$. R Square model 1 sebesar 0,623, Orientasi Belanja dan Kualitas web memiliki R Square $62,3 \%$. Sisanya $37,7 \%$ disebabkan oleh variabel lain diluar kedua variabel tersebut. R Square model 2 sebesar 0,322, Orientasi Belanja dan Kualitas web memiliki R Square 32,2\%. Sisanya $67,8 \%$ disebabkan oleh variabel lain diluar kedua variabel tersebut. 


\section{UJI SOBEL}

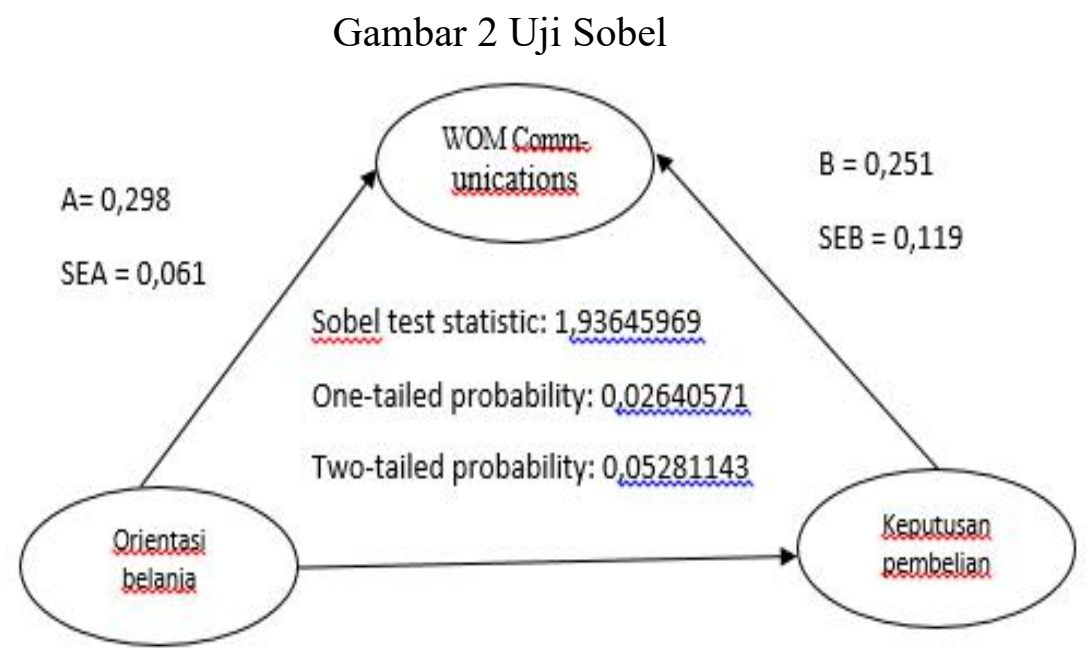

Dari hasil perhitungan sobel dapat dilihat bahwa nilai sobel test pada one-tailed probability 0,02640571 >0,05 maka dpt disimpulkan bahwa word of mouth communications bisa menjadi variabel intervening antara orientasi belanja dan keputusan pembelian

Gambar 2 Uji Sobel

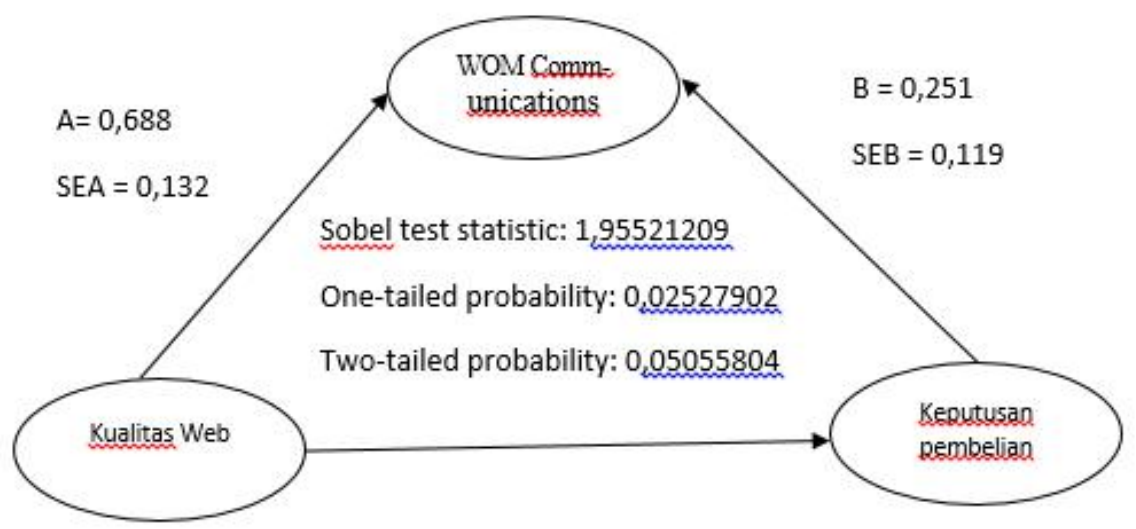

Dari hasil perhitungan sobel dapat dilihat bahwa nilai sobel test pada one-tailed probability 0,02527902 >0,05 maka dpt disimpulkan bahwa word of mouth communications bis a menjadi variabel intervening antara orientasi belanja dan keputusan pembelian

\section{PEMBAHASAN}

\section{Pengaruh Orientasi Belanja terhadap Word of Mouth Communications}

Hasil penelitian ini menunjukan bahwa uji parsial ( $\mathrm{t}$ hitung) orientasi belanja berpengaruh positif dan signifikan terhadap word of mount communications . Dengan ini media internet yang semakin maju membantu produk shopee banyak di kenal menunjukan bahwa ketika seorang konsumen sudah merasa percaya terhadap online shop maka akan menimbulkan rasa ketertarikan dan merekomendasikan terhadap konsumen lain untuk mengikuti berbelanjadi shopee dan pembelanja produk shopee dapat dilakukan di rumah membantu memudakan pengguna untuk berbelanja, menjadikan penguna sangat terbantu. 


\section{Pengaruh Kualitas Web terhadap Word of Mouth Communications}

Hasil penelitian ini menunjukan bahwa uji parsial (t hitung) kualitas web berperngaruh positif dan signifikan terhadap word of mount communications. Hal ini menunjukan bahwa pengunjung shopee tentunya lebih tertarik membicarakan produk yang dimuat dalam website yang menarik dan memiliki estetika. Ketika kualitas informasi yang yang terdapat dalam website tersebut dapat dipercaya maka seseorang individu dapat merekomendasikan kepada orang lain. Dengan dibantu fitur-fitur yang mudah di pahami dan dengan media internet, marketplace shopee yang semakin maju membuat shopee semakin di kenal masyarakat.

\section{Pengaruh Orientasi belanja terhadap Keputusan Pembelian}

Hasil penelitian ini menunjukan bahwa uji parsial (t hitung) orientasi belanja berpengaruh positif dan tidak signifikan terhadap keputusan pembelia. Berdasarkan penelitian dan hasil diatas menunjukan bahwa kemudahan dalam pembelanjaan mempengaruhi konsumen untuk memutuskan pembelian suatu produk, kemudahan dalam pembayaran yang bisa dilakukan saat bersamaan barang itu sampai membuat konsumen merasa puas dan semakin percaya denga produk shopee.

\section{Pengaruh Kualitas Web terhadap Keputusan Pembelian}

Hasil penelitian ini menunjukan bahwa uji parsial (t hitung) kualitas web berperngaruh positif dan tidak signifikan terhadap ord of Mouth Communication. Berdasarkan penelitian dan hasil diatas menunjukan bahwa dalam adanya kualitas web yang dinilai baik oleh konsumen akan mempengaruhi keputusan pembelian suatu produk disitus online. Kemudahan dalam penggunaan aplikasi shopee memudahkan konsumen tidak kebinggugan dan dengan tampilan yang bervarian membuat ketertarikan konsumen membeli produk shopee.

\section{Pengaruh Word of Mouth Communications terhadap Keputusan Pembelian}

Hasil penelitian ini menunjukan bahwa uji parsial ( $\mathrm{t}$ hitung) word of mouth communications berpengaruh positif dan signifikan terhadap keputusan pembelian. Berdasarkan penelitian diatas menunjukan bahwa word of mouth communicatios sangat berpengaruh dalam penjualan, kejujuran dalam menjual, tanggung jawab dan komitmen yang tinggi dari apa yang dipasarkan merupakan aspek yang harus dipegang erat-erat oleh para penjual agar pelanggan mereka tidak ragu merekomendasikan ke orang lain untuk membeli produk yang ditawarkan din shopee.

\section{Pengaruh Orientasi Belanja Terhadap Keputusan Pembelian Melalui Word Of Mouth Communications}

Pengujian hipotesis ini dilakukan untuk membuktikan pengaruh orientasi belanja terhadap keputusan pembelian melalui word of mouth communications sebagai variabel intervening. Dari hasil perhitungan sobel tes diketahui one-tailed probability sebesar $0,000<$ 0,05, hal ini menunjukkan bahwa word of mouth communications berpengaruh dan mampu menjadi variabel intervening diantara orientasi belanja dan keputusan pembelian. Hasil penelitian ini menunjukan bahwa orientasi belaja sangat berpengruh terhadap keputusan pembelian, melalui word of mouth communications. Dengan kemudahan pembelanjaan yang dapat dilakukan dimanapun memudahlan konsumen dalam memutuskan pembelia, tidak hanya itu saja semakin word of mouth yang tinggi maka akan memberikan dampak secara signifikan terhadap minat beli konsumen.

\section{Pengaruh Kualitas Web Terhadap Keputusan Pembelian Melalui Word Of Mouth Communications}

Pengujian hipotesis ini dilakukan untuk membuktikan pengaruh kualitas web terhadap keputusan pembelian melalui word of mouth communications sebagai variabel intervening. Dari 
hasil perhitungan sobel tes diketahui one-tailed probability sebesar $0,000<0,05$, hal ini menunjukkan bahwa word of mouth communications berpengaruh dan mampu menjadi variabel intervening diantara kualitas web dan keputusan pembelian. Hasil penelitian ini menunjukan bahwa kualitas web sangat penting ketika seseorang melakukan pembelian secara tidak terencana, kemudahan dalam pengoprasian aplikasi shopee juga sangat membantu konsumen dalam menentukan pembelian yang akan di beli. Semakin baik komentar yang diberikan dan semakin menarik foto yang diunggah semakin besar pegaruh untuk pengguna yang akan memutuskan pembelian pada produk shopee.

\section{KESIMPULAN}

Berdasarkan hasil penelitian dan pembahasan maka dapat diambil kesimpulan bahwa orientasi belanja berpengaruh terhadap word of mouth communications. kualitas web berpengaruh terhadap word of mouth communications. orientasi belanja dan kualitas web berpengaruh positif dan tidak signifikan terhadap keputusan pembelian. word of mouth communications berpengaruh positif dan signifikan terhadap keputusan pembelian. Variabel orientasi belanja berpengaruh terhadap keputusan pembelian melalui word of mouth communications. Variabel kualitas web mampu mempengaruhi keputusan pembelian melalui word of mouth communications.

\section{SARAN}

\section{Perusahaan}

Perusahaan shopee harus meningkatkan kepercayaan konsumen dalam pembelian, harus lebih inovatif dan kreatif lagi dalam menggembangkan kualitas informasi dalam penyediaan informasi produk yang akurat dan menambah fitur yang ada di dalamnya, guna produknya dapat menjadi produk pilihan yang dipertimbangkan oleh konsumen untuk melakukan pembelian. Perusahaan shopee harus lebih meningkatkan respon dari konsumen dan lebih merespon keluh kesah dari pembelian produk shopee agar konsumen agar konsumen shopee tidak kecewa dengan pelayanan yang diberikan dan menambah produk-produk yang inovatif, berkualitas dari segi bahan dan lebih up to date lagi, guna produk shoppe bisa diterima baik di masyarakat dan konsumen puas dengan produk shopee.

\section{Peneliti}

Untuk kedepannya dapat merancang, menyusun penelitian yang dapat menciptakan penelitian yang lebih baik dari pada penelitian yang dilakukan saat ini, dan dapat memiliki referensi yang lebih banyak dan lebih baik lagi.

\section{DAFTAR PUSTAKA}

Alhasanah, J. (2014). PENGARUH KEGUNAAN, KUALITAS INFORMASI DAN KUALITAS INTERAKSI LAYANAN WEB E-COMMERCE TERHADAP KEPUTUSAN PEMBELIAN ONLINE (Survei pada Konsumen www.getscoop.com). Jurnal Administrasi Bisnis, 15(2).

Dewi Ratnasari, V. A. (2019). PENGARUH KEPERCAYAAN, ORIENTASI BELANJA DAN HARGA TERHADAP KEPUTUSAN PEMBELIAN SECARA ONLINE. Journal of Chemical Information and Modeling, 53(9), 1689-1699. https://doi.org/10.1017/CBO9781107415324.004

Kurnia, D. (2016). PENGARUH KEPERCAYAAN, ORIENTASI BELANJA, DAN KUALITAS LAYANAN TERHADAP KEPUTUSAN PEMBELIAN BUSANA SECARA ONLINE (Studi 
Pada Mahasiswa Universitas Lampung).

Kurniawan, R., Kusumawati, A., \& Priambada, S. (2018). PENGARUH KUALITAS WEBSITE (WEBQUAL) TERHADAP KEPERCAYAAN DAN DAMPAKNYA PADA KEPUTUSAN PEMBELIAN PADA WEBSITE E-COMMERCE ( Studi pada Konsumen PT . B ). Jurnal Administrasi Bisnis, 62(1), 198-206.

Lotulung, S. C., Lapian, J., \& Moniharapon, S. (2015). Pengaruh Kualitas Produk, Harga, Dan Wom (Word of Mouth) Terhadap Keputusan Pembelian Handphone Evercoss Pada Cv.Tristar Jaya Globalindo Manado. Jurnal Riset Ekonomi, Manajemen, Bisnis Dan Akuntansi, 3(3), 817-826.

Rahayu, D. D. (2014). PENGARUH WORD OF MOUTH DAN BRAND COMMUNITY KOMUNITAS SEPAK BOLA DI PEKAN BARU TERHADAP BAND IMAGE. JURNAL EKONOMI, 2014(June), 1-2. https://doi.org/10.1038/132817a0

Ria Amalia Fhonna \& Sorayanti Utami. (2019). Pengaruh Electronic Word Of Mouth Terhadap Keterlibatan Keputusan Pembelian Dan Kepercayaan Sebagai Pemediasi Pada Konsumen Shopee Di Universitas Syiah Kuala. Journal of Chemical Information and Modeling, 53(9), 1689-1699. https://doi.org/10.1017/CBO9781107415324.004

Widyanita, F. A. (2018). ANALISIS PENGARUH KUALITAS PELAYANAN E-COMMERCE SHOPEE TERHADAP KEPUASAN KONSUMEN SHOPEE INDONESIA. 